\title{
The Perception of the City as a Growth Machine and Space of Flows
}

\author{
Ana Rusta \\ French-Albanian School "Ernest Koliqi", Tirana, Albania \\ Email: anatogu_88@yahoo.es
}

Doi:10.5901/mjss.2017.v8n1p453

\begin{abstract}
Two of the main features of the city over the last 50 years include intense urbanization and large scale growth. These two phenomena have produced new social, political and economical dynamics that have radicalized our understanding of the city. Many disciplines, among which urban sociology, are facing a crisis of old paradigms to explain these innovations. Consequently, contemporary urban sociology has articulated two new paradigms that try to explain and analyze the new processes of global urbanization. In the view of new models of urban growth, under intense globalization process, these phenomena are completely renovating the perception of the city under the models of a growth machine and the space of flows. These two views attempt to explain and understand the dynamic growth and changes in contemporary cities. In this essay we will put expose a critical analysis of the city as a growth machine and space of flows of the most important authors that unfold a latest development of the city in contemporary conditions. The main authors whose work will be addressed here are Harvey Molotch and Manuel Castells. Molotch reveals a new perception of the city as a growth machine that is based on the terms of strong economic urban development, while Castells introduces the notion of "network city" and "space of flows" for a new social structure to explain the complexity of connection within and between the cities (global cities). Under the new conditions, the perception of the city is understood as the space of flows that create global networks and new forms of interaction.
\end{abstract}

Keywords: growth machine, city, space of flows, global city, network

\section{Introduction}

There are various perceptions of the city being influenced from different methodology, disciplines and paradigms during the history of urban thought. One of the prospects that will be treated is related to the analysis of the city as a locus, which is defined not only by the physical and economical factors but also from the social and communicative ones. Urban sociologists such as Louis Wirth and Harvey Moloch have analysed the perception of the city as a machine of growth, where, besides the positive aspects that the economic capital provides to us, it also causes problems which are associated with impacts on the environment and economic inequality.

In addition, under the new conditions of globalization and the development of technological communication, a new theory by Manuel Castells will be shaped, known as space of flows. This prespective will highlight the idea that the perception of the city not only has radically changed but it has also produced a dynamic of extension, not only between urban and rural but also in the way of its formation as non-physical entity with global borders. The basic categories and concepts of the way how the city is being perceived, such as: time, urban areas and the relationships of social interaction, have been totally changed, due to the influence of modern communication technologies.

\section{The City as a Growth Machine}

Different conventional definitions of the city, urban areas or metropolis have resulted in various analysis of the urban systems and the problems associated with them. One of the most interesting approaches to determine urban areas begins since the "40s with the notion of Wirth. His paradigm is related to the historical and social conditions that the american metropolis had at that time, which then became a model of interpretation for Europe. Thus, Wirth being conditioned by intensive process of urbanization at the time, perceived the city not as a dimension of social structure which involved the power and hierarchy of classes, but as an equation with physical terms with three main element: "number, density and heterogeneity." According to Wirth, there are a number of sociological propositions concerning the relationship between (a) number of population, (b) density of settlement and (c) heterogeneity of inhabitants and group life, which can be formulated on the basis of observation and research (Wirth,1938,10).

At this perspective, Wirth not only was seeking to mark the typology of the city and what actually the city is but 
also to emphasize the difference between the rural space and the situation of the city before the intensive process of the modern urbanization. Consequently, one of the basic qualities of urbanization is the appearance of the increasing size of number and growth of population and its heterogeneity. "Thus the larger, the more densely populated, and the more heterogeneous a community, the more accentuated the characteristics associated with urbanism will be" (Wirth, 1938, 9).

In this aspect the intensive urbanization was considered to be not only an element that was developed at the inner part of the city, but also as a process which redefined and reshaped its own meaning. In geometric terms, the vectorial growth of the number constitutes the essential element of what it is named a city, where "to to say that large numbers are necessary to constitute a city means, of course, large numbers in relation to a restricted area or high density of settlement" (Wirth, 1938,9).

Nevertheles, although the Wirth's access became one of the dominant paradigms in the interpretation of the urban space, it had a deeper impact at the further changes of the city which appeared later on.

At this point of view, with the great economic development that the city was undergoing, a new access naturally was produced, but which took into consideration the main principles of Wirth's model.

Around the early 80's, when western cities had achieved an economic and material prosperity, a new paradigm of the conception of the city arose, which took into consideration these economic factors. Taking as empirical model the American city, Molotch "...speculate that the political and economic essence of virtually any given locality, in the present American context, is growth" (Molotch, 1976, 309-310).

Historically, Molotch was the first one who stressed the idea of the city as a growth machine, a basic locality which contributes in its own economical growth and development, but also as a state in general. According to him, empirically "the clearest indication of success at growth is a constantly rising urban-area population- a symptom of pattern ordinarily comprising an initial expansion of basic industries followed by an expanded labor force, a rising scale of retail and wholesale commerce, more far-flung and increasingly intensive land development, higher population density, and increased levels of financial activity" ( Molotch, 1976,310).

However, this model of urban growth related to the city is too complex also at a political and social level. Stressing the economic dimension of the nature of the city this aspect involves directly a dimension of power and politics. "Thus, because the city is a growth machine, it draws a special sort of person into its politics" (Molotch, 1976, 317). In a more concrete social sense, every part of the land in the urban space is an aggregate of interests and each territory should not be seen as a demarcation of topographical features but also as a mosaic of competing interests associated with land capable of action and strategic kualicion. But this process is also one of the reasons of social conflict that this pattern of the city growth creates. "First is the increasing suspicion that in many areas, at many historical moments, growth benefits only a small proportion of local residents" (Molotch, 1976,318). Së dyti, "growth almost brings with it the obvious problems of increased air and water pollution, traffic congestion, and overtaxing of natural amenities" (Molotch, 1976,318).

\section{The City as a Space of Flows}

Under the phenomenon of the intensive urbanization and suburbanization the city was experiencing deep social and urban dynamics. In this aspect, not only the economic capital but also the technological one was radically changing the conception and perception related to the urban space. One of the main researchers who contributed in his work was Manuel Castell.

From the social point of view, he stated that: "the critical factor in the new urban processes, in Europe as elsewhere, is the fact that urban space is increasingly differentiated in social terms, while being functionally interrelated beyond physical contiguity. There follows the separation between symbolic meaning, location of functions, and the social appropriation of space in the metropolitan area" (Castells, 2010, 433-434). Meanwhile, according to him, in an epistemological aspect, "to consider the city as projection of society on space is both an indispensable starting point and too elementary an approach" (Castell, 1977, 115). So in a complex and complete meaning the area ".... is not a reflection of society, it is its expression. In other words: space is not a photocopy of society, it is society. Spatial forms and processes are formed by the dynamics of the overall social structure." (Castells, 2010, 440-441).

From this point of view, the changed social conditions related to the city according to Castell, involve a new kind of conception and interpretation of the area and land in an urban sense. He states that the usage of new technologies, the collapse of communist states and the emergence of various social movements have resulted in the creation of a new society, the society of network. Thus, in todays social meaning, "the new society is made up of networks [....] network is a set of interconnected nodes" (Castell, 2000, 695).

On the other hand, a new concept responds to the new social and technological conditions, that of space of flows. The ".... idea that there is a new spatial form characteristic of social practices that dominate and shape the network 
society: the space of flows. The space of flows is the material organisation of time-sharing social practices that work through flows. By flows I understand purposeful, repetitive, programmable sequences of exchange and interaction between physically disjointed positions held by social actors in the economic, political, and symbolic structures of society" (Castells, 2010, 442).

Thus, from the social aspect "the theory of space of flows from the implicit assumption that societies are asymmetrically organized around the dominant interests specific to each social structure. The space of flows is not the only spatial logic of our societies. It is, however, the dominant spatial logic because it is the spatial logic of the dominant interests/functions in our society" (Castells, 2010, 445). However, the space of flows has its own typology by radically transforming the concept of place and time related to the urban area, where "... function and power in our societies are organized in the space of flows, the structural domination of its logic essentially alters the meaning and dynamic of places" (Castells, 2010, 458). "[The] networks of discontiguous places in interaction with a diverse range of localities are the components of the new sociospatial structure.... A social structure made up of netwroks is an interactive system, constantly on the move. Social actors constituted as networks add and substract components, which bring with them into the acting network new values and interests defined in terms of their matrix in the changing social structure" (Castell, $2000,697)$.But, with the change of social structure under the regime of space of flows, the vector time and place also change, as a result of the new technological vector.

"With the diffusion of electronically based communication technologies, territorial contiguity ceases to be a precondition for the simultaneity of interactive social practices. But the "death of distance" is not the end of spatial dimension of society... The space of flows... is made of electronic circuits and information systems, but it is also made of territories, physical places, whose functional or symbolic meaning depends on their connection to a network, rather than on its specific characteristics as localities. The space of flows is made of bits and pieces of places, connected by telecommunications, fast transportation, and information systems, and marked by symbols and spaces of intermediation (such as airports, international hotels, business centers, symbolized by de-localized architecture)" (Castell, 2000, 696).

Furthermore, the new virtual and distance communication technology shapes and organizes a new kind of social humus in the urban space.

"The Information Age is ushering in a new urban form, the informational city..[and]".... because of the nature of the new society, based upon knowledge, or organized around networks, and partly made up of flows, the informational city in not a form but a process, a process characterized by structural domination of the space of flows" (Castells, 2010, 429).

In this dynamic, the later is increasingly replacing the space of places. Castells, states that our society has evolved into a situation with three main features: information, globalization and network. In a broader geographical sense, typologically the space of flows acts the same as the electronic communication networks that is related to the development of a hierarchy of cities (global cities) which become strategic distributors of the information at a global level, thus forming what is named "global city".

More specifically, "the global city is made of territories that in different cities ensure the management of global economy and of global information networks.....so the global city is a network of noncontiguous territories, reunited around the task of managing globalism by networks that transcend locality" (Castell, 2000, 697). But the typology of this city is more complicated than it appears because "the global city is not a place, but a process" (Castells, 2010, 417).

This concept is not only perceived as a definitive product, but as an open and dynamic process which constantly changing over time.

\section{Conclusions}

Even though these paradigms presented a restricted perspective of the perception of the city, however, they constitute a good and empirically justified model, which help us understand urban space in today's global conditions. They stressed the fact that often the technological innovation and the economic capital create a deep impact not only in the conception of the city but also in the way categories and relations within and outside the city radically change shape.

Furthermore, these perspectives stress the fact that in today's specific conditions, new problems have appeared which require innovative instruments to be solved on a scale that overcomes the physical limits of the city, permanently changing the physiognomy and dynamics that it creates. 


\section{References}

Castells, M. (1977). The Urban Question. A Marxist Approach. London: Edward Arnold (Publishers) Ltd

Castells, M. (2000). Toward a Sociology of Network Society, Contemporary Sociology. American Sociological Assocation, 29 (5), 696699.

Castells, M. (2010). The Rise of the Network Society.USA: Blackwell Publishing

Molotch, H. (1976). The city as a growth machine: Toward a political economy of place. American Journal of Sociology, 82(2), 309-332.

Wirth, L. (1938). Urbanism as a way of life. American Journal of Sociology, 44(1), 1-24. 